\title{
Computed Tomography-Based Thrombus Imaging for the Prediction of Recanalization after Reperfusion Therapy in Stroke
}

\author{
Ji Hoe Heo, ${ }^{a}$ Kyeonsub Kim, ${ }^{a}$ Joonsang Yoo, ${ }^{a}$ Young Dae Kim, ${ }^{a}$ Hyo Suk Nam, ${ }^{a}$ Eung Yeop Kim ${ }^{b}$ \\ a Department of Neurology, Yonsei University College of Medicine, Seoul, Korea \\ ${ }^{b}$ Department of Radiology, Gachon University Gil Medical Center, Incheon, Korea
}

The prediction of successful recanalization following thrombolytic or endovascular treatment may be helpful to determine the strategy of recanalization treatment in acute stroke. Thrombus can be detected using noncontrast computed tomography (CT) as a hyperdense artery sign or blooming artifact on a T2*-weighted gradient-recalled image. The detection of thrombus using CT depends on slice thickness. Thrombus burden can be determined in terms of the length, volume, and clot burden score. The thrombus size can be quantitatively measured on thin-section CT or CT angiography/magnetic resonance angiography. The determination of thrombus size may be predictive of successful recanalization/non-recanalization after intravenous thrombolysis and endovascular treatment. However, cutoffs of thrombus size for predicting recanalization/non-recanalization are different among studies, due to different methods of measurements. Thus, a standardized method to measure the thrombus is necessary for thrombus imaging to be useful and reliable in clinical practice. Software-based measurements may provide a reliable and accurate assessment. The measurement should be easy and rapid to be more widely used in practice, which could be achieved by improvement of the user interface. In addition to prediction of recanalization, sequential measurements of thrombus volume before and after the treatment may also be useful to determine the efficacy of new thrombolytic drugs. This manuscript reviews the diagnosis of thrombus, prediction of recanalization using thrombus imaging, and practical considerations for the measurement of thrombus burden and density on CT.

\author{
Correspondence: Ji Hoe Heo \\ Department of Neurology, Yonsei \\ University College of Medicine, \\ 50-1 Yonsei-ro, Seodaemoon-gu, \\ Seoul 03722, Korea \\ Tel: +82-2-2228-1605 \\ Fax: +82-2-393-0705 \\ E-mail:jhheo@yuhs.ac
}

Received: October 11, 2016

Revised: January 3, 2017

Accepted: January 11, 2017

This research was supported by a grant from the Korea Health Technology R\&D Project through the Korea Health Industry Development Institute, funded by the Ministry of Health and Welfare, Republic of Korea (HI15C2814).

The authors have no financial conflicts of interest.

Keywords Thrombus, Imaging, Tomography, X-ray computed, Therapeutic thrombolysis,

Endovascular procedure

\section{Introduction}

Imaging studies, including computed tomography (CT) and magnetic resonance imaging (MRI), are essential for the diagnosis and treatment of patients with acute stroke. Imaging methods in stroke have been developed and evolved for the accurate diagnosis of infarction/hemorrhage and arterial occlusion and the assessment of perfusion and collateral circulation. Since the successful introduction of reperfusion therapy in stroke, one of the key issues has been the selection of patients who would benefit from the recanalization therapy. ${ }^{12}$ Thus, the development and use of imaging techniques in acute stroke have been focused on identifying the presence and extent of potentially salvageable areas upon recanalization and the durability of ischemic areas until recanalization. This imaging strategy has also been used for patient selection in several major clinical trials. ${ }^{3-6}$ However, to rescue the salvageable areas, the occluded artery should be opened after recanalization treatment. Meanwhile, favorable clinical outcomes are not achieved in many patients treated with intravenous (IV) tissue plasminogen activator (tPA) 
or endovascular treatment. ${ }^{7-9}$ Therefore, the prediction of successful recanalization following thrombolytic or endovascular treatment is important. This prediction may also be helpful in determining the recanalization treatment strategy.

Imaging methods for the diagnosis of stroke and salvageable areas target the brain tissues and arteries. However, the thrombus is the ultimate target of recanalization treatment. In this regard, thrombus imaging evaluation is essential for predicting the response to IV tPA or endovascular treatment. ${ }^{10}$ Various preclinical and clinical studies on direct thrombus imaging have been introduced in a recent review. "While the thrombus can be detected using noncontrast CT (NCCT), gradient-recalled echo (GRE), and susceptibility-weighted imaging (SWI) in humans (Supplementary Figure 1), most studies that investigated the prediction of thrombus imaging for recanalization have been performed using CT. Compared to MRI, CT is more easily and widely used, and CT-based thrombus imaging provides more precise information on thrombus burden. Furthermore, the density (Hounsfield unit [HU]) may represent the characteristics/composition of the thrombus to some extent. Recently, as endovascular thrombectomy has been more widely used for acute stroke, we can obtain the thrombi occluding the intracranial arteries and know more about their histological characteristics and relationship with thrombus densities on CT.

This manuscript reviews the imaging diagnosis of thrombus on $\mathrm{CT}$, prediction of recanalization using CT-based thrombus imaging, methods for the quantitation of thrombus burden and density on $\mathrm{CT}$, and histological and imaging characteristics of thrombus in acute stroke.

\section{Detection of the thrombus}

Thrombus is detected on NCCT as a hyperdense artery sign. The diagnosis of thrombus on NCCT depends on the slice thick- ness. Conventional CT using 5- or 10-mm slice thickness has a limitation in displaying thrombi in the intracranial arteries, including the MCA, which has a diameter $<3 \mathrm{~mm} .{ }^{12}$ In 51 patients with infarction in the middle cerebral artery (MCA) or anterior cerebral artery (ACA) territory, thrombi were identified in 45 patients (88\%) on thin-section (1.25- or 1-mm thickness) NCCT, but only in 16 patients $(31 \%)$ on standard $5-\mathrm{mm} \mathrm{NCCT.}{ }^{13}$ This finding was replicated by another study that compared the detection of clot between 5-mm NCCT and 0.625-mm NCCT in 54 patients with MCA occlusion. ${ }^{14}$ The thin-section NCCT is sensitive, reliable, and accurate for the detection of thrombi. ${ }^{15}$

\section{Prediction of recanalization based on thrombus size}

\section{Prediction in intravenous tPA thrombolysis}

Recanalization rates after IV tPA in stroke depend on the location of the occluded cerebral arteries. IV tPA-induced recanalization is achieved more frequently in the MCA M2 occlusion than in the proximal MCA or the internal carotid artery occlusion. ${ }^{16,17}$ Thrombus volume differs according to the location of occluded arteries. For example, the average thrombus volume is largest in the internal carotid artery occlusion, followed by MCA M1 and MCA M2 occlusion. ${ }^{18}$ Thus, thrombus volume may be a critical factor for successful recanalization in patients with acute stroke treated with IV tPA.

Several studies investigated whether the determination of thrombus size can predict successful recanalization/non-recanalization after IV tPA treatment in patients with stroke (Table 1). Kim and colleagues first investigated the association between successful recanalization and thrombus volume, which was measured automatically using a 3-dimensional imaging software, in 34 patients with MCA occlusion. ${ }^{19}$ This study included patients who were treated with IV tPA or IV tPA plus intra-arte-

Table 1. Thrombus burden and recanalization (IV thrombolysis)

\begin{tabular}{|c|c|c|c|c|c|}
\hline Author (year) & Patient No. & Artery & $\begin{array}{c}\text { Imaging } \\
\text { (CT thickness, mm) }\end{array}$ & Method & Association with recanalization \\
\hline Kim, $2006^{19}$ & 8 & MCA & NCCT (1.25) & Volume & No $(58.8 \pm 52.7 \text { vs. } 44.36 \pm 66.5, P=0.564)^{*}$ \\
\hline Riedel, $2011^{20}$ & 138 & Not specified & NCCT (2.5) & Length & Yes (cut-off 8 mm, $P<0.001$ ) \\
\hline Shobha, $2013^{21}$ & 41 & M1 & NCCT (5.0) & Length & Yes ( $86 \%$ vs. $37 \%$ vs. $0 \%, P<0.001)^{+}$ \\
\hline Behrens, $2014^{22}$ & 96 & Any intracranial & CTA, MRA & Length & $\begin{array}{l}\text { Yes }(0 \mathrm{R} 0.78,95 \% \mathrm{Cl} 0.65-0.95, P=0.014)^{+} \\
\text {No recanalization in thrombus }>16 \mathrm{~mm}\end{array}$ \\
\hline Rohan, $2014^{23}$ & 80 & M1 & CTA & Length & $\begin{array}{l}\text { Yes (cut-off } 12 \mathrm{~mm} \text {, sensitivity 0.67, specificity } \\
0.71,0 \mathrm{R} 4.81,95 \% \mathrm{Cl} 1.86-12.40 \text { ) }\end{array}$ \\
\hline Strbian, $2014^{24}$ & 103 & BA & CTA, MRA & Length & Yes (15 [6-25] vs. 5.5 [3.6-15.4], $P<0.001)$ \\
\hline
\end{tabular}

$\mathrm{CT}$, computed tomography; MCA, middle cerebral artery; NCCT, noncontrast computed tomography; CTA, computed tomography angiography; MRA, magnetic resonance angiography; $\mathrm{OR}$, odds ratio; $\mathrm{Cl}$, confidence interval; $\mathrm{BA}$, basilar artery.

${ }^{*}$ Recanalization vs. nonrecanallization, $\mathrm{mm}^{3} ;{ }^{\dagger}$ thrombus length $<10 \mathrm{~mm}$ vs. $10-19 \mathrm{~mm}$ vs. $20 \mathrm{~mm}$, percent for the disappearance of hyperdense artery sign on follow-up scan; ${ }^{\ddagger}$ decreased probability of recanalization per $\mathrm{mm}$. 
rial (IA) urokinase, and no association was found between the thrombus volume and recanalization. Negative association in this study might be ascribed to the small sample size and the use of heterogeneous recanalization treatment modalities. In the subsequent studies, thrombus length was determined on NCCT or maximum intensity projection images using $\mathrm{CT}$ angiography (CTA)/MR angiography (MRA), and the length of thrombus was significantly associated with successful recanalization after IV tPA treatment. ${ }^{20-24}$ They attempted to determine the optimal cutoff for predicting non-recanalization. However, the optical cutoff was different among studies varying from 8-16 mm (Table 1). Furthermore, they evaluated recanalization at different time points after IV tPA infusion. ${ }^{19}$

\section{Prediction in endovascular treatment}

The association between thrombus size and successful recanalization after endovascular treatment has also been investigated. The results of the studies were inconsistent (Table 2). It might be because of the different mechanical devices used, different methods used to determine thrombus size, and small number of cases included..$^{21,25-30}$ However, in a recent study of a relatively large number of patients who were treated with a stent retriever, higher clot burden scores were associated with increased likelihood of recanalization. ${ }^{2}$ Smaller thrombi may be more easily retrieved with fewer attempts using a Solitaire device. However, the predictability of thrombus size for successful recanalization seems less remarkable in endovascular treatment than in IV tPA treatment.

\section{Practical considerations for the measurement of thrombus size}

\section{Thrombus volume}

Thrombus size can be determined in terms of volume, length, or burden score (Table 3). The thrombus volume is measured using imaging analysis software. ${ }^{18,31}$ This software-based measurement of thrombus volume provides the most accurate and reliable information on thrombus burden, irrespective of the angioarchitecture. Rapid and easy measurements of thrombus volume and density are now feasible using a 3-dimensional software. Briefly, after the detection of thrombus on NCCT via the process of pixel pigmentation, a region of interest (ROI) is defined within any portion of thrombus using a brush tool. Then, automatic region growing is performed in the range of HU 40-100, and the volume and mean $\mathrm{HU}$ are automatically calculated and shown. This software may be used in emergent situations. ${ }^{32}$

\section{Thrombus length on noncontrast CT}

Thrombus length can also be used to estimate the thrombus size. The accurate determination of thrombus length on standard

Table 2. Thrombus burden and recanalization (endovascular treatment)

\begin{tabular}{|c|c|c|c|c|c|c|}
\hline Author (year) & $\begin{array}{l}\text { Patient } \\
\text { No. }\end{array}$ & Artery & $\begin{array}{l}\text { Primary treatment } \\
\text { modality }\end{array}$ & $\begin{array}{c}\text { Imaging } \\
\text { (CT thickness, mm) }\end{array}$ & Method & Association with recanalization* \\
\hline \multirow[t]{2}{*}{ Kim, $2006^{19}$} & 12 & MCA & IAT & NCCT (1.25) & Volume & No $(39.2 \pm 37.4 \text { vs. } 123.5 \pm 169.1, P=0.2)^{*}$ \\
\hline & 14 & & $\mathrm{IVT}+\mathrm{IAT}$ & & & No $(106.1 \pm 94.5 \text { vs. } 79.2 \pm 61.8, P=0.482)^{*}$ \\
\hline Spiotta, $2014^{25}$ & 122 & MCA & Penumbra, & CTA & Length & No $(13.3 \pm 10.0 \text { vs. } 13.5 \pm 7.6, P=0.92)^{*}$ \\
\hline Shobha, $2013^{21}$ & 35 & M1 & Not specified & NCCT (5.0) & Length & Yes $(60 \% \text { vs. } 33 \% \text { vs. } 50 \%, P<0.002)^{+}$ \\
\hline \multirow[t]{4}{*}{ Mokin, $2014^{26}$} & 41 & ICA, M1, M2 & Solitaire & NCCT (5.0) & & No \\
\hline & & & & & CBS & $6.6 \pm 1.1$ vs. $6.6 \pm 1.8, P=0.87$ \\
\hline & & & & & Volume, & $101.0 \pm 81.0$ vs. $89.8 \pm 65.0, P=0.43$ \\
\hline & & & & & Length & $12.2 \pm 4.7$ vs. $14.0 \pm 6.0, P=0.44$ \\
\hline Jindal, $2014^{27}$ & 28 & $\mathrm{M} 1, \mathrm{ICA}$ & $\begin{array}{l}\text { Penumbra, Solitaire, } \\
\text { Trevo }\end{array}$ & SWI, CTA, NCCT & length & No, $P=0.378$ \\
\hline Soize, $2015^{28}$ & 153 & Any intracranial & Solitaire & GRE & Length & $\begin{array}{l}15.4 \pm 8.4 \text { vs. } 20.1 \pm 9.0, P=0.00003 \text {, cut-off } \\
18 \text { (sensitivity } 0.70, \text { specificity } 0.57,0 R 3.09 \text { ) }\end{array}$ \\
\hline Angermailer, 2016 & 63 & MCA, ICA & Stent retriever & CTA & CBS & No (7 [6-8] vs. $6[4.5-7.0], P=0.08)$ \\
\hline Mokin, 2016 & 69 & MCA, ICA & Solitaire & CTA & CBS & No $(6.5 \pm 1.7$ vs. $7.3 \pm 1.3, P=0.25)$ \\
\hline Treurniet, 2016 & 499 & MCA, ICA & Solitaire & CTA & CBS & $\begin{array}{l}\text { Yes (model A: OR, 1.25, 95\% Cl, 1.13-1.81, } \\
\text { model B: OR 1.27, 95\% Cl, 1.14-1.41) }\end{array}$ \\
\hline
\end{tabular}

Values are mean \pm standard deviation, median [interquartile range], or odds ratio (OR) with 95\% confidence interval (CI).

The volume is presented as $\mathrm{mm}^{3}$, and the length is presented as $\mathrm{mm}$.

CT, computed tomography; MCA, middle cerebral artery; IAT, intra-arterial thrombolysis; NCCT, noncontrast computed tomography; IVT, intravenous thrombolysis; ICA, internal carotid artery; M1, M1 segment of MCA; CTA, computed tomography angiography; SWI, susceptibility-weighted imaging; GRE, gradientrecalled echo; $\mathrm{CBS}$, clot burden score.

${ }^{*}$ Recanalization $(\mathrm{TICl} \geq 2)$ vs. nonrecanallization $(\mathrm{TICl}<2)$; ${ }^{+}$thrombus length $<10 \mathrm{~mm}$ vs. $10-19 \mathrm{~mm}$ vs. $20 \mathrm{~mm}$, percent for the disappearance of hyperdense artery sign on follow-up scan; ${ }^{*}$ odds ratio (OR) and 95\% confidence interval (CI) based on two different statistical models. 
Table 3. Methods to measure the thrombus size and burden

\begin{tabular}{|c|c|c|c|c|}
\hline & \multirow{2}{*}{ Volume } & \multicolumn{2}{|c|}{ Length } & \multirow{2}{*}{ Clot burden score } \\
\hline & & On NCCT & On angiography & \\
\hline Imaging tool & Thin-section NCCT & Thin-section NCCT & CTA, MRA & CTA, MRA \\
\hline Thrombus measurement & Direct & Direct & $\begin{array}{l}\text { Indirect based on absence of } \\
\text { contrast opacification }\end{array}$ & $\begin{array}{l}\text { Indirect based on absence of } \\
\text { contrast opacification }\end{array}$ \\
\hline Measurement method & $\begin{array}{l}\text { Pixel segmentation, region } \\
\text { growing, and automatic } \\
\text { calculation using 3-dimen- } \\
\text { sional imaging software }\end{array}$ & $\begin{array}{l}\text { Pixel segmentation and } \\
\text { Euclidean length measure- } \\
\text { ment after reducing to } \\
\text { skeleton using software }\end{array}$ & $\begin{array}{l}\text { Measurement using free- } \\
\text { hand curve function on MIP } \\
\text { image after post processing } \\
\text { procedure }\end{array}$ & $\begin{array}{l}\text { Visual scoring based on } \\
\text { determining the absence of } \\
\text { contrast opacification in the } \\
\text { predefined locations }\end{array}$ \\
\hline Measurable artery & Any intracranial artery & $\begin{array}{l}\text { Usually proximal segment of } \\
\text { intracranial artery }\end{array}$ & Any intracranial artery & Anterior circulation \\
\hline Accuracy & $\begin{array}{l}\text { Close to actual thrombus } \\
\text { burden (volume) }\end{array}$ & $\begin{array}{l}\text { Close to actual thrombus } \\
\text { length }\end{array}$ & Can be overestimated & $\begin{array}{l}\text { Approximate burden } \\
\text { Can be overestimated }\end{array}$ \\
\hline Practical use & Requires software & Requires software & Requires postprocessing & $\begin{array}{l}\text { Easy and rapid by visual } \\
\text { assessment }\end{array}$ \\
\hline
\end{tabular}

NCCT, noncontrast computed tomography; CTA, computed tomography angiography; MRA, magnetic resonance angiography; MIP, multiple projection images.
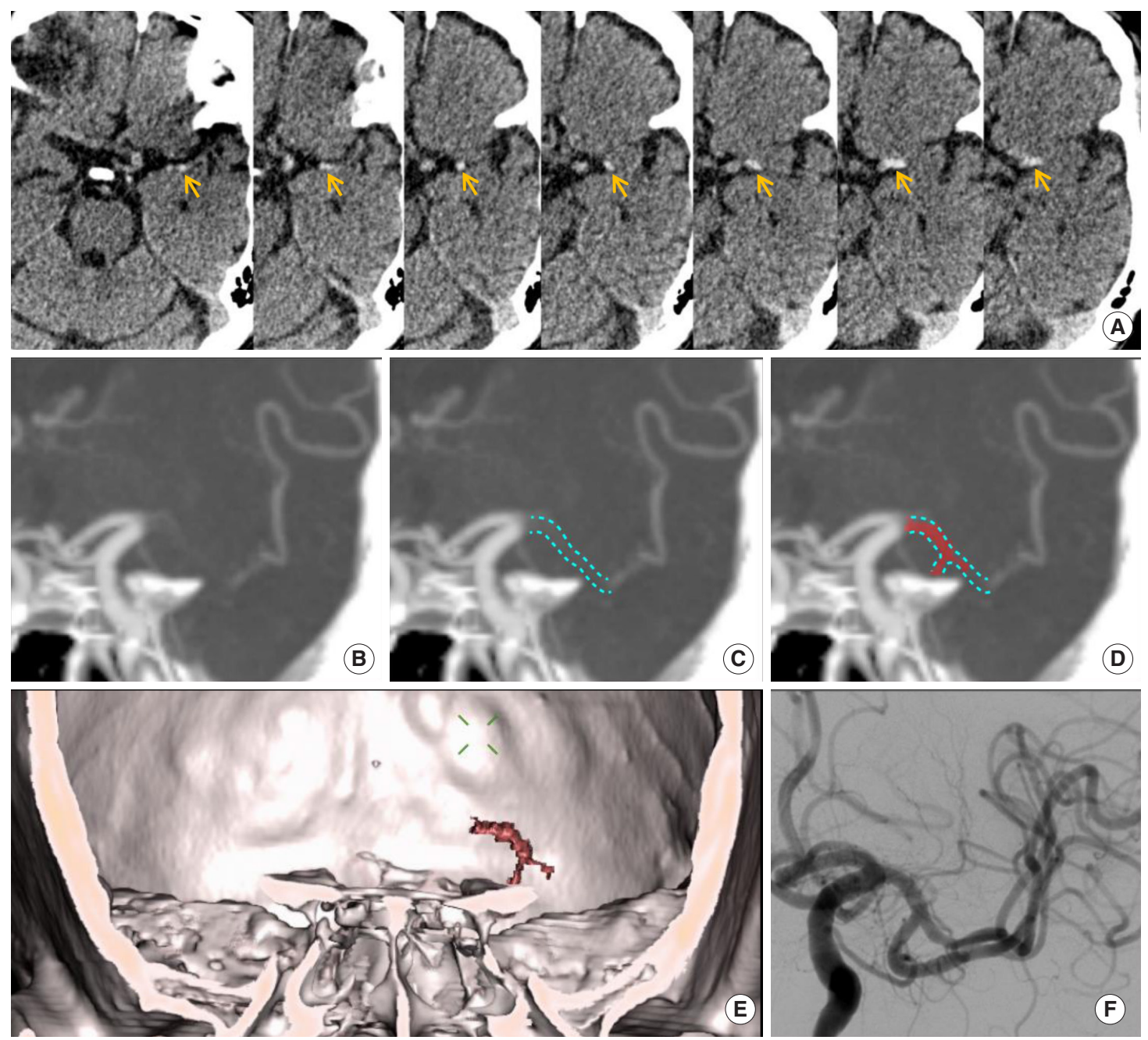

Figure 1. A representative case for the measurement of thrombus length. Hyperdense artery sign is seen on thin-section noncontrast computed angiography (CT) scan (arrows) (A). Measurement of thrombus length on this plain CT is almost impossible (A). An imaginary line (green dotted line) is drawn to measure the length on CT angiography (B, C). The actual location of the thrombus (D), which was visualized using 3-dimensional software (E), was superimposed on the imaginary lines of the actual angioarchitecture based on the angiographic findings after successful retrieval of thrombi using Solitaire stent (F). The thrombus length is overestimated on CT angiography, and thrombus in the bifurcated branch cannot be measured (D). 
NCCT is very difficult (Figure 1A), and depends on the slice thickness of the CT scan. Accordingly, the length is first determined on thin-section NCCT via image processing procedures: pixel segmentation, region growing, reducing to a skeleton by applying a topography-preserving morphological thinning operation, and calculation of the maximum Euclidean length of the resulting skeleton. ${ }^{12}$ Based on this method, a thrombus length of $8 \mathrm{~mm}$ on 2.5$\mathrm{mm}$ NCCT was suggested as a cut-off of predicting non-recanalization after IV tPA treatment. ${ }^{20}$ In fact, the THERAPY trial (The Randomized, Concurrent Controlled Trial to Assess the Penumbra System's Safety and Effectiveness in the Treatment of Acute Stroke), which tested the effect of aspiration thrombectomy, included a thrombus length of $8 \mathrm{~mm}$ or longer as inclusion criteria. ${ }^{33}$

\section{Thrombus length on CT angiography}

Thrombus length may be measured on CTA, MRA, delayed gadolinium-enhanced T1 image, or SWI. ${ }^{34,35}$ The freehand curve function is used to measure thrombus length on maximum intensity projection (MIP) images. ${ }^{23}$ The measurements on CTA or MRA are based on an arbitrarily drawn line in the absence of information on the actual angioarchitecture. Determination of the distal end of thrombus is dependent on the backflow from collateral circulation. Thus, the length on CTA or MRA cannot be adequately measured in cases that lack the backflow and is therefore frequently overestimated. Obtaining delayed images using multiphase CTA or dynamic CTA may be helpful in reducing overestimation due to the backflow issue..$^{34}$ In addition, accurate measurements of length either on NCCT or CTA/MRA are limited in curved or branched arteries. In cases with different arterial diameters, thrombus length may not precisely represent the actual burden of thrombus (Figure 1). Due to these limitations, the determination of thrombus length is usually limited to the MCA M1 segment in most cases.

\section{Clot burden score}

The clot burden score is a 10-point scoring system to quantify the thrombus burden for anterior circulation. For scoring, major arteries are allotted for the presence of contrast opacification on CTA. One or two points are subtracted for the absence of contrast opacification in the infraclinoid internal carotid artery (ICA) (2), supraclinoid ICA (2), proximal M1 (2), distal M1 (2), M2 branches (one each), and A1 (1). ${ }^{36}$ This scoring system provides easy and rapid, yet only approximate, information on thrombus burden and can be used for the occlusion in anterior circulation only. The clot burden score is also influenced by the backflow from collateral circulation; hence, clot burden may be overestimated in cases with insufficient collaterals. ${ }^{2}$ However, overestimated clot burden because of the lack of contrast filling due to poor collaterals may strengthen the prognostic value of this clot burden score because poor collaterals are known to be associated with poor outcomes. ${ }^{2}$

\section{Prediction of recanalization based on the thrombus density}

Thrombus density on CT may reflect the constituents of the thrombus to some extent. Red blood cells (RBCs) in the thrombus increase attenuation on CT. A hyperdense artery sign is seen more commonly in RBC-dominant or mixed thrombi than in fibrin-rich thrombi. ${ }^{37,38} \mathrm{RBC}$-rich thrombi are also seen on MRI. The RBC components in thrombi induce ferromagnetic field distortion, which results in a blooming artifact on GRE and SWI.

Thrombi are traditionally differentiated into "red thrombi" or RBC-fibrin-rich thrombi and "white thrombi" or platelet-fibrinrich thrombi. It is assumed that the constituents of thrombi differ in large artery atherosclerosis and in cardioembolism because they have different mechanisms of thrombus formation. The introduction of mechanical thrombectomy has allowed the comparison of the histological features of retrieved thrombi from patients with acute stroke. Earlier studies compared thrombi using hematoxylin-eosin staining and found no histological difference between arterial and cardiac thrombi. ${ }^{38,39}$ Subsequent studies used hematoxylin-eosin and special or immunohistochemical staining to define the constituents of thrombi more distinctly. However, findings were inconsistent among studies on RBC dominance in arterial thrombi ${ }^{40-42}$ or cardiac thrombi ${ }^{43,44}$ (Supplementary Table 1).

The microscopic distribution of platelets and fibrin within the thrombus may be different between arterial and cardiac thrombi. In arterial thrombi, RBC masses are located in the center with a thin outer covering of fibrin-platelet and platelet aggregates in the edge of the thrombi. However, in cardiac thrombi, platelet aggregates are scattered throughout the thrombi with large amounts of fibrin. ${ }^{41}$ Although the simple average of thrombus $\mathrm{HU}$ does not provide consistent information on the prediction of thrombus histology and the origin of thrombi (cardiac or arterial), higher HU on CT may suggest a higher proportion of RBC in the thrombus. However, a blooming artifact on MRI can provide information on the presence of thrombus only.

Different thrombus characteristics may affect the response to IV tPA. Previous studies showed that thrombus density (HU) is predictive of recanalization (Table 4). Successful recanalization was achieved more frequently in patients with thrombi of higher HU than those of lower HU after IV tPA or endovascular treatment. ${ }^{19,26,45-47}$ However, in studies that assessed the degree of thrombus resolution on thin-section NCCT taken before and af- 
Table 4. Thrombus density on CT and recanalization

\begin{tabular}{|c|c|c|c|c|c|c|c|c|}
\hline & \multirow{2}{*}{$\begin{array}{l}\text { Thickness } \\
(\mathrm{mm})\end{array}$} & \multirow[b]{2}{*}{ Method of ROI drawing } & \multirow[b]{2}{*}{$\begin{array}{c}\text { Recanalization } \\
\text { assessment }\end{array}$} & \multirow{2}{*}{$\begin{array}{l}\text { Treatment } \\
\text { modality }\end{array}$} & \multirow{2}{*}{$\begin{array}{l}\text { Patient } \\
\text { No. }\end{array}$} & \multicolumn{3}{|c|}{ Recanalization mean \pm SD HU (relative $\mathrm{HU}^{*}$ ) } \\
\hline & & & & & & Yes & No & $\begin{array}{l}P \text {-value } \\
\text { (cut-off') }^{+}\end{array}$ \\
\hline \multirow[t]{3}{*}{ Kim, $2006^{19}$} & \multirow[t]{3}{*}{1.25} & \multirow[t]{3}{*}{ Automatic } & \multirow[t]{3}{*}{ Within 1 day } & IVT & 8 & $55 \pm 3.2$ & $48.4 \pm 3.2$ & 0.043 \\
\hline & & & & IAT & 12 & $53.8 \pm 2.9$ & $49.5 \pm 2.4$ & 0.025 \\
\hline & & & & IVT+IAT & 14 & $53.2 \pm 2.7$ & $47.3 \pm 2.9$ & $\begin{array}{l}0.009 \\
(<49.5)\end{array}$ \\
\hline Puig, $2011^{45}$ & 3.0 & Manually outlined the margin & 1 hour & $\mathrm{IVT}$ & 45 & $\begin{array}{c}49.3 \\
(1.57 \pm 0.23)\end{array}$ & $\begin{array}{c}42.1 \\
(1.11 \pm 0.15)\end{array}$ & $\begin{array}{l}<0.001 \\
(<1.382)\end{array}$ \\
\hline \multirow[t]{3}{*}{ Moftakhar, $2012^{46}$} & \multirow[t]{3}{*}{2.5} & \multirow[t]{3}{*}{ Manually drawn within thrombus } & \multirow[t]{3}{*}{ Not specified } & IVT & 45 & 1.58 & 1.39 & 0.01 \\
\hline & & & & IAT & 43 & 1.66 & 1.4 & 0.006 \\
\hline & & & & $\mathrm{IVT}+\mathrm{EVT}$ & 77 & 1.7 & 1.3 & $<0.0001$ \\
\hline Mokin, $2014^{26}$ & 5.0 & Manually outlined the margin & at EVT & IVT+stent & 41 & $\begin{array}{c}49.9 \pm 7.6 \\
(1.2 \pm 0.2)\end{array}$ & $\begin{array}{c}43.8 \pm 6.6 \\
(1.0 \pm 0.1)\end{array}$ & $\begin{array}{l}0.01 \\
0.03\end{array}$ \\
\hline Nielsten, $2014^{47}$ & 1.0 & Manually drawn small circles & $1-5$ days & IVT & 88 & $\begin{array}{c}63.1 \pm 10.7 \\
(1.54 \pm 0.23)\end{array}$ & $\begin{array}{c}52.2 \pm 9.5 \\
(1.29 \pm 0.20)\end{array}$ & $\begin{array}{c}<0.0001 \\
(<56.5,<1.38)\end{array}$ \\
\hline Spiotta, $2014^{25}$ & 4.8 & Manually drawn small circles & at EVT & $\begin{array}{l}\text { IVT/IAT } \\
\text { IVT+Penumbra }\end{array}$ & 137 & $57.1 \pm 16.3$ & $68.7 \pm 43.2$ & 0.22 \\
\hline
\end{tabular}

$\mathrm{CT}$, computed tomography; SD, standard deviation; ROI, region of interest; HU, hounsfield unit; IVT, intravenous thrombolysis; IAT, intra-arterial thrombolysis; EVT, endovascular treatment.

${ }^{*}$ Relative $\mathrm{HU}$ is calculated as $\mathrm{HU}$ of symptomatic side/HU of asymptomatic side; ${ }^{+}$Cut-off for persistent occlusion.

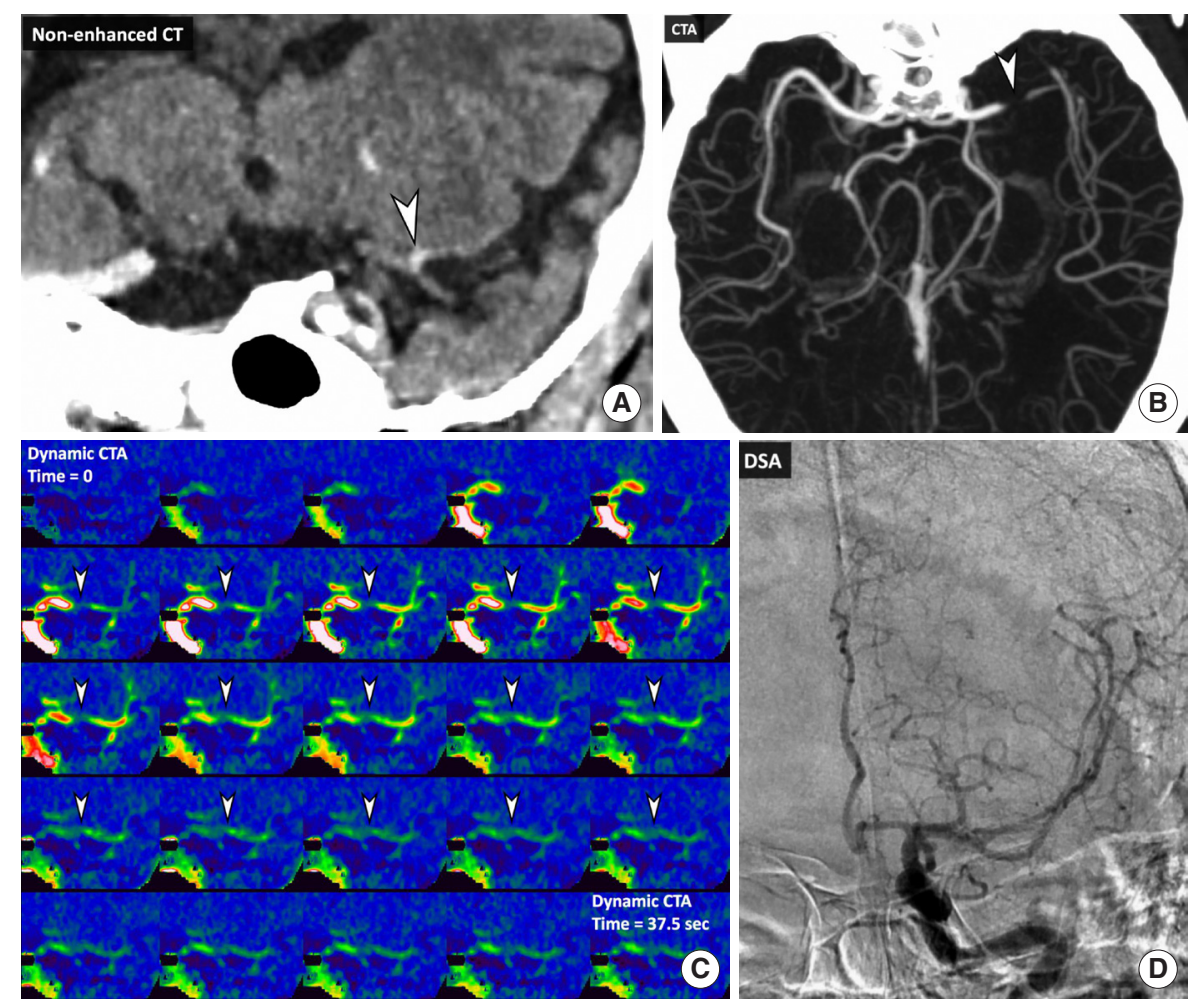

Figure 2. A representative case with perviousness. A 78-year-old man who presented with right-side weakness and sensory aphasia. Non-enhanced CT shows a "hyperdense" thrombus (arrowhead) in the bifurcation of the left middle cerebral artery (MCA), which corresponds to the occlusion on computed tomography angiography (CTA) (arrowhead) (,$B$ ). Dynamic CTA shows gradual enhancement in the thrombus (arrowheads). This gradual enhancement indicates the perviousness of a contrast agent into the thrombus (C). Intravenous tissue plasminogen activator (tPA) was administered after obtaining dynamic CTA. Digital subtraction angiography taken 2 hours after tPA demonstrates complete recanalization of left MCA (D).

ter IV tPA infusion, the thrombus density was not associated with the degree of thrombus resolution. ${ }^{32,48}$ As mentioned earlier, the proportion and distribution of each component in thrombus are quite heterogeneous. In addition, recanalization is influenced by other factors including thrombus volume and the degree of collaterals. Therefore, further studies are necessary to ascertain 
the role of averaged density of thrombus on NCCT in predicting recanalization.

In a recent study, thrombus density was simultaneously measured on thin-section NCCT and CTA. ${ }^{49}$ Then, the perviousness of thrombus was determined by calculating the increase in $\mathrm{HU}$ on CTA compared with NCCT. The increase in HU $\geq 23$ was associated with recanalization after IV tPA treatment. ${ }^{49}$ Perviousness to the contrast agent may reflect less compact thrombi that are more pervious to tPA, which could enhance the action of tPA within the thrombi (Figure 2). Thus, the comparison of simultaneously measured densities of thrombi on NCCT and CTA may be helpful in predicting the response to tPA.

\section{Practical considerations for the measurement of thrombus density}

Thrombus density on NCCT has been measured using different methods. To calculate density, the ROI should be defined. The thrombus margin was defined by manually outlining the margin of thrombus in each section. Then, the values of $\mathrm{HU}$ in each section were summed and divided by the total number of sections. ${ }^{45}$ This method is difficult to perform in a clinical setting and may underestimate the density since low attenuated areas in the peripheral area of the thrombus might be included when manually outlining the thrombus. In another study, small circles were manually drawn three times within the thrombus, and their mean values were calculated. ${ }^{47}$ This method is easy but may overestimate the density.

The prediction of recanalization using the average value of thrombus density should rely on how the density is measured. The distribution of RBCs, fibrin, and platelets within the thrombus are quite heterogeneous among patients and stroke subtypes. ${ }^{41}$ In fact, thrombi of arterial origin show a thin outer covering of platelet-fibrin and a zone of platelet aggregation at the edge or periphery of the thrombus. ${ }^{41}$ While responses to recanalization treatment in platelet-rich areas may be different from RBC-fibrin rich areas, platelet-fibrin area, or zone within the thrombus may be missed by manually defining the area. Therefore, the entire area of thrombus should be included for averaging HU. While defining the ROI is critical for the accurate calculation of mean $\mathrm{HU}$, it is not easy to manually outline the margin of thrombi precisely. Thus, the prediction of recanalization based on thrombus density has some practical limitations for accurate measurements, which needs careful attention for the interpretation of findings in previous studies. These limitations can be overcome substantially by using 3-dimensional software, which automatically defines the ROI based on the $\mathrm{HU}$ of pixels so that the entire area of thrombus can be included and averaged.

\section{Thrombus imaging to determine the efficacy of thrombolytic drugs}

The degree of thrombus resolution is a direct indicator of the efficacy of thrombolytic drugs. The effect of IV tPA has been determined by quantitatively assessing the changes in thrombus volume using 3-dimensional software on NCCT before and after IV tPA infusion. 32,48 The median volume decreased by $20 \%$, and thrombus was completely resolved in $8 \%$ of patients after tPA infusion. The thrombus resolution increased by $9 \%$ per $10 \mathrm{mg}$ increment of tPA, indicating that the degree of thrombus resolution was associated with the total dose of tPA. ${ }^{48}$ The effect of tPA is also time-dependent. The probability of thrombus resolution was inversely correlated with the time from symptom onset to tPA treatment. These findings shed light on the importance of time course in IV tPA treatment. Earlier treatment is important not only for the rescue of tissues but also for better thrombus resolution. Hence, "Time is clot as well as brain."

Of note, thrombus volume paradoxically increased in about $20 \%$ of patients. ${ }^{48}$ The reason for this paradoxical increase in thrombus volume after tPA treatment is still speculative. However, reocclusion after initially successful recanalization occurs in about $14-34 \%$ of patients treated with IV thrombolysis..$^{50-54}$ The mechanism of reocclusion is associated with paradoxical activation of platelets and thrombin by $\mathrm{tPA} .{ }^{55}$ Reocclusion is more common in cases with residual thrombus. ${ }^{51}$ Some thrombi, including platelet-rich thrombi, may be resistant to tPA, which is fibrin-specific. The increase in thrombus volume after tPA treatment may be associated with tPA-induced paradoxical activation of platelets and generation of thrombin in patients with tPA-resistant thrombi.

\section{Conclusions and perspectives}

Imaging of thrombus has evolved from a mere diagnostic technique for the presence of clots in intracranial arteries to a quantitative and qualitative assessment tool. In addition, further understanding of the clot histology and comparison of thrombus imaging are now possible as we can get actual thrombi using clot-retrieval devices. Several methods have been suggested to assess the thrombus. However, measured thrombus volume and density differ with the methods used. Thus, it is necessary to understand the pitfalls of each measurement method. Quantitative and qualitative information on thrombi can help predict recanalization after IV tPA and endovascular treatment. Direct endovascular treatment without IV IPA treatment can be considered in cases with large thrombi that are predicted not to be recanalized by IV tPA. Sequential measurements of thrombus volume 
before and after thrombolytic treatment are also useful to test the efficacy of new drugs. However, a standardized method to measure the thrombus is necessary for thrombus imaging to be used more widely and reliably. Furthermore, if thrombus imaging is to be used in clinical practice for predicting recanalization after the reperfusion therapy, physicians should be able to measure thrombus volume and density easily and rapidly. Since quantitative measurements of thrombus size and density require software, the user interface and availability of software should be improved.

\section{References}

1. Lee JS, Demchuk AM. Choosing a hyperacute stroke imaging protocol for proper patient selection and time efficient endovascular treatment: lessons from recent trials. J Stroke 2015; 17:221-228.

2. Treurniet KM, Yoo AJ, Berkhemer OA, Lingsma HF, Boers AM, Fransen PS, et al. Clot burden score on baseline computerized tomographic angiography and intra-arterial treatment effect in acute ischemic stroke. Stroke 2016;47:2972-2978.

3. Davis SM, Donnan GA, Parsons MW, Levi C, Butcher KS, Peeters $A$, et al. Effects of alteplase beyond $3 \mathrm{~h}$ after stroke in the Echoplanar Imaging Thrombolytic Evaluation Trial (EPITHET): a placebo-controlled randomised trial. Lancet Neurol 2008;7: 299-309.

4. Parsons $M$, Spratt N, Bivard A, Campbell B, Chung K, Miteff $F$, et al. A randomized trial of tenecteplase versus alteplase for acute ischemic stroke. N Engl J Med 2012;366:1099-1107.

5. Campbell BC, Mitchell PJ, Kleinig TJ, Dewey HM, Churilov L, Yassi $N$, et al. Endovascular therapy for ischemic stroke with perfusion-imaging selection. N Engl J Med 2015;372:11091118.

6. Kidwell CS, Jahan R, Gornbein J, Alger JR, Nenov V, Ajani Z, et al. A trial of imaging selection and endovascular treatment for ischemic stroke. N Engl J Med 2013;368:914-923.

7. Wardlaw JM, Murray V, Berge E, del Zoppo G, Sandercock P,

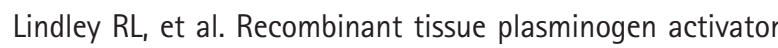
for acute ischaemic stroke: an updated systematic review and meta-analysis. Lancet 2012;379:2364-2372.

8. Campbell BC, Donnan GA, Lees KR, Hacke W, Khatri P, Hill MD, et al. Endovascular stent thrombectomy: the new standard of care for large vessel ischaemic stroke. Lancet Neurol 2015;14: 846-854.

9. Hong KS, Ko SB, Lee JS, Yu KH, Rha JH. Endovascular recanalization therapy in acute ischemic stroke: updated meta-analysis of randomized controlled trials. J Stroke 2015;17:268-281.

10. Gasparian GG, Sanossian N, Shiroishi MS, Liebeskind DS. Imag- ing of occlusive thrombi in acute ischemic stroke. Int J Stroke 2014;10:298-305.

11. Kim J, Park JE, Nahrendorf M, Kim DE. Direct thrombus imaging in stroke. J Stroke 2016;18:286-296.

12. Riedel $\mathrm{CH}$, Jensen $U$, Rohr $A$, Tietke $M$, Alfke $K$, Ulmer $S$, et al. Assessment of thrombus in acute middle cerebral artery occlusion using thin-slice nonenhanced Computed Tomography reconstructions. Stroke 2010;41:1659-1664.

13. Kim EY, Lee SK, Kim DJ, Suh SH, Kim J, Heo JH, et al. Detection of thrombus in acute ischemic stroke: value of thin-section noncontrast-computed tomography. Stroke 2005;36:27452747.

14. Riedel CH, Zoubie J, Ulmer S, Gierthmuehlen J, Jansen O. Thinslice reconstructions of nonenhanced CT images allow for detection of thrombus in acute stroke. Stroke 2012;43:2319-2323.

15. Mair G, Boyd EV, Chappell FM, von Kummer R, Lindley RI, Sandercock $P$, et al. Sensitivity and specificity of the hyperdense artery sign for arterial obstruction in acute ischemic stroke. Stroke 2015;46:102-107.

16. Lee KY, Han SW, Kim SH, Nam HS, Ahn SW, Kim DJ, et al. Early recanalization after intravenous administration of recombinant tissue plasminogen activator as assessed by pre- and postthrombolytic angiography in acute ischemic stroke patients. Stroke 2007;38:192-193.

17. Rha JH, Saver JL. The impact of recanalization on ischemic stroke outcome: a meta-analysis. Stroke 2007;38:967-973.

18. Kim EY, Yoo E, Choi HY, Lee JW, Heo JH. Thrombus volume comparison between patients with and without hyperattenuated artery sign on CT. AJNR Am J Neuroradiol 2008;29:359362.

19. Kim EY, Heo JH, Lee SK, Kim DJ, Suh SH, Kim J, et al. Prediction of thrombolytic efficacy in acute ischemic stroke using thinsection noncontrast CT. Neurology 2006;67:1846-1848.

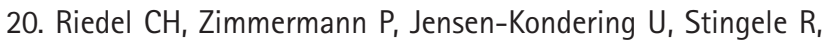
Deuschl G, Jansen 0 . The importance of size: successful recanalization by intravenous thrombolysis in acute anterior stroke depends on thrombus length. Stroke 2011;42:1775-1777.

21. Shobha N, Bal S, Boyko M, Kroshus E, Menon BK, Bhatia R, et al. Measurement of length of hyperdense MCA sign in acute ischemic stroke predicts disappearance after IV tPA. J Neuroimaging 2013;24:7-10.

22. Behrens $L$, Mohlenbruch M, Stampfl S, Ringleb PA, Hametner $C$, Kellert $L$, et al. Effect of thrombus size on recanalization by bridging intravenous thrombolysis. Eur J Neurol 2014;21:14061410.

23. Rohan V, Baxa J, Tupy R, Cerna L, Sevcik P, Friesl M, et al. Length of occlusion predicts recanalization and outcome after intravenous thrombolysis in middle cerebral artery stroke. Stroke 
2014:45:2010-2017.

24. Strbian D, Sairanen T, Silvennoinen H, Salonen O, Lindsberg PJ. Intravenous thrombolysis of basilar artery occlusion: thrombus length versus recanalization success. Stroke 2014;45:17331738.

25. Spiotta AM, Vargas J, Hawk H, Turner R, Chaudry MI, Batten-

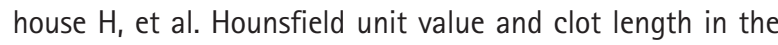
acutely occluded vessel and time required to achieve thrombectomy, complications and outcome. J Neurointerv Surg 2013; 6:423-427.

26. Mokin M, Morr S, Natarajan SK, Lin N, Snyder KV, Hopkins LN, et al. Thrombus density predicts successful recanalization with Solitaire stent retriever thrombectomy in acute ischemic stroke. J Neurointerv Surg 2014;7:104-107.

27. Jindal G, Miller T, Shivashankar R, Mitchell J, Stern BJ, Yarbrough $K_{1}$ et al. Relationship of thrombus length to number of stent retrievals, revascularization, and outcomes in acute ischemic stroke. J Vasc Interv Radiol 2014;25:1549-1557.

28. Soize $S$, Batista AL, Rodriguez RC, Trystram D, Tisserand M, Turc $G$, et al. Susceptibility vessel sign on $T 2^{*}$ magnetic resonance imaging and recanalization results of mechanical thrombectomy with stent retrievers: a multicentre cohort study. Eur J Neurol 2015;22:967-972.

29. Angermaier $A$, Michel $P$, Khaw AV, Kirsch $M$, Kessler $C$, Langner S. Intravenous thrombolysis and passes of thrombectomy as predictors for endovascular revascularization in ischemic stroke. J Stroke Cerebrovasc Dis 2016;25:2488-2495.

30. Mokin M, Levy El, Siddiqui AH, Goyal M, Nogueira RG, Yavagal $\mathrm{DR}$, et al. Association of clot burden score with radiographic and clinical outcomes following Solitaire stent retriever thrombectomy: analysis of the SWIFT PRIME trial. J Neurointerv Surg 2016. Epub ahead of print.

31. Kosior JC, Idris S, Dowlatshahi D, Alzawahmah M, Eesa M,

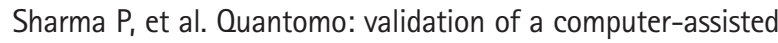
methodology for the volumetric analysis of intracerebral haemorrhage. Int J Stroke 2011;6:302-305.

32. Kim YD, Nam HS, Kim SH, Kim EY, Song D, Kwon I, et al. Timedependent thrombus resolution after tissue-type plasminogen activator in patients with stroke and mice. Stroke 2015;46: 1877-1882.

33. Mocco J, Zaidat 00, von Kummer R, Yoo AJ, Gupta R, Lopes D, et al. Aspiration Thrombectomy After Intravenous Alteplase Versus Intravenous Alteplase Alone. Stroke 2016;47:23312338.

34. Yan S, Chen $\mathrm{O}, \mathrm{Xu}$ M, Sun J, Liebeskind DS, Lou M. Thrombus length estimation on delayed gadolinium-enhanced T1. Stroke 2016;47:756-761.

35. Weisstanner C, Gratz PP, Schroth G, Verma RK, Kochl A, Jung
$\mathrm{S}$, et al. Thrombus imaging in acute stroke: correlation of thrombus length on susceptibility-weighted imaging with endovascular reperfusion success. Eur Radiol 2014;24:17351741.

36. Puetz V, Dzialowski I, Hill MD, Subramaniam S, Sylaja PN, Krol $A$, et al. Intracranial thrombus extent predicts clinical outcome, final infarct size and hemorrhagic transformation in ischemic stroke: the clot burden score. Int J Stroke 2008;3: 230-236.

37. Brinjikji W, Duffy $S$, Burrows $A$, Hacke W, Liebeskind D, Majoie $C B$, et al. Correlation of imaging and histopathology of thrombi in acute ischemic stroke with etiology and outcome: a systematic review. J Neurointerv Surg 2016. Epub ahead of print.

38. Liebeskind DS, Sanossian N, Yong WH, Starkman S, Tsang MP, Moya $A L$, et al. CT and MRI early vessel signs reflect clot composition in acute stroke. Stroke 2011;42:1237-1243.

39. Marder VJ, Chute DJ, Starkman S, Abolian AM, Kidwell C, Liebeskind $D$, et al. Analysis of thrombi retrieved from cerebral arteries of patients with acute ischemic stroke. Stroke 2006; 37:2086-2093.

40. Niesten JM, van der Schaaf IC, van Dam L, Vink A, Vos JA, Schonewille WJ, et al. Histopathologic composition of cerebral thrombi of acute stroke patients is correlated with stroke subtype and thrombus attenuation. PLoS One 2014;9:e88882.

41. Ahn SH, Hong R, Choo IS, Heo JH, Nam HS, Kang HG, et al. Histologic features of acute thrombi retrieved from stroke patients during mechanical reperfusion therapy. Int J Stroke 2016; $11: 1036-1044$.

42. Boeckh-Behrens T, Kleine JF, Zimmer C, Neff F, Scheipl F, Pelisek J, et al. Thrombus histology suggests cardioembolic cause in cryptogenic stroke. Stroke 2016;47:1864-1871.

43. Sato $Y$, Ishibashi-Ueda $H$, Iwakiri $T$, Ikeda $Y$, Matsuyama $T$, Hatakeyama $K$, et al. Thrombus components in cardioembolic and atherothrombotic strokes. Thromb Res 2012;130:278-280.

44. Kim SK, Yoon W, Kim TS, Kim HS, Heo TW, Park MS. Histologic analysis of retrieved clots in acute ischemic stroke: correlation with stroke etiology and gradient-echo MRI. ANNR Am J Neuroradiol 2015;36:1756-1762.

45. Puig J, Pedraza S, Demchuk A, Daunis IEJ, Termes H, Blasco G, et al. Quantification of thrombus hounsfield units on noncontrast CT predicts stroke subtype and early recanalization after intravenous recombinant tissue plasminogen activator. AJNR Am J Neuroradiol 2011;33:90-96.

46. Moftakhar P, English JD, Cooke DL, Kim WT, Stout C, Smith WS, et al. Density of thrombus on admission CT predicts revascularization efficacy in large vessel occlusion acute ischemic stroke. Stroke 2012;44:243-245.

47. Niesten JM, van der Schaaf IC, van der Graaf Y, Kappelle $\sqcup$, 
Biessels GJ, Horsch AD, et al. Predictive value of thrombus attenuation on thin-slice non-contrast CT for persistent occlusion after intravenous thrombolysis. Cerebrovasc Dis 2014;37: 116-122.

48. Nam HS, Kim EY, Kim SH, Kim YD, Kim J, Lee HS, et al. Prediction of thrombus resolution after intravenous thrombolysis assessed by CT-based thrombus imaging. Thromb Haemost 2012; 107:786-794.

49. Santos EM, Dankbaar JW, Treurniet KM, Horsch AD, Roos YB,

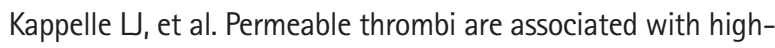
er intravenous recombinant tissue-type plasminogen activator treatment success in patients with acute ischemic stroke. Stroke 2016;47:2058-2065.

50. Alexandrov AV, Grotta JC. Arterial reocclusion in stroke patients treated with intravenous tissue plasminogen activator. Neurology 2002;59:862-867.

51. Heo JH, Lee KY, Kim SH, Kim DI. Immediate reocclusion follow- ing a successful thrombolysis in acute stroke: a pilot study. Neurology 2003;60:1684-1687.

52. Janjua N, Alkawi A, Suri MF, Qureshi Al. Impact of arterial reocclusion and distal fragmentation during thrombolysis among patients with acute ischemic stroke. AJNR Am J Neuroradiol 2008;29:253-258.

53. Qureshi Al, Siddiqui AM, Kim SH, Hanel RA, Xavier AR, Kirmani

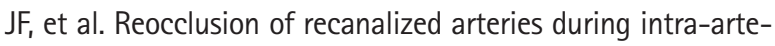
rial thrombolysis for acute ischemic stroke. AJNR Am J Neuroradiol 2004;25:322-328.

54. Saqqur M, Molina CA, Salam A, Siddiqui M, Ribo M, Uchino K, et al. Clinical deterioration after intravenous recombinant tissue plasminogen activator treatment: a multicenter transcranial Doppler study. Stroke 2007;38:69-74.

55. Lee KY, Heo JH, Lee SI, Yoon PH. Rescue treatment with abciximab in acute ischemic stroke. Neurology 2001;56:1585-1587. 

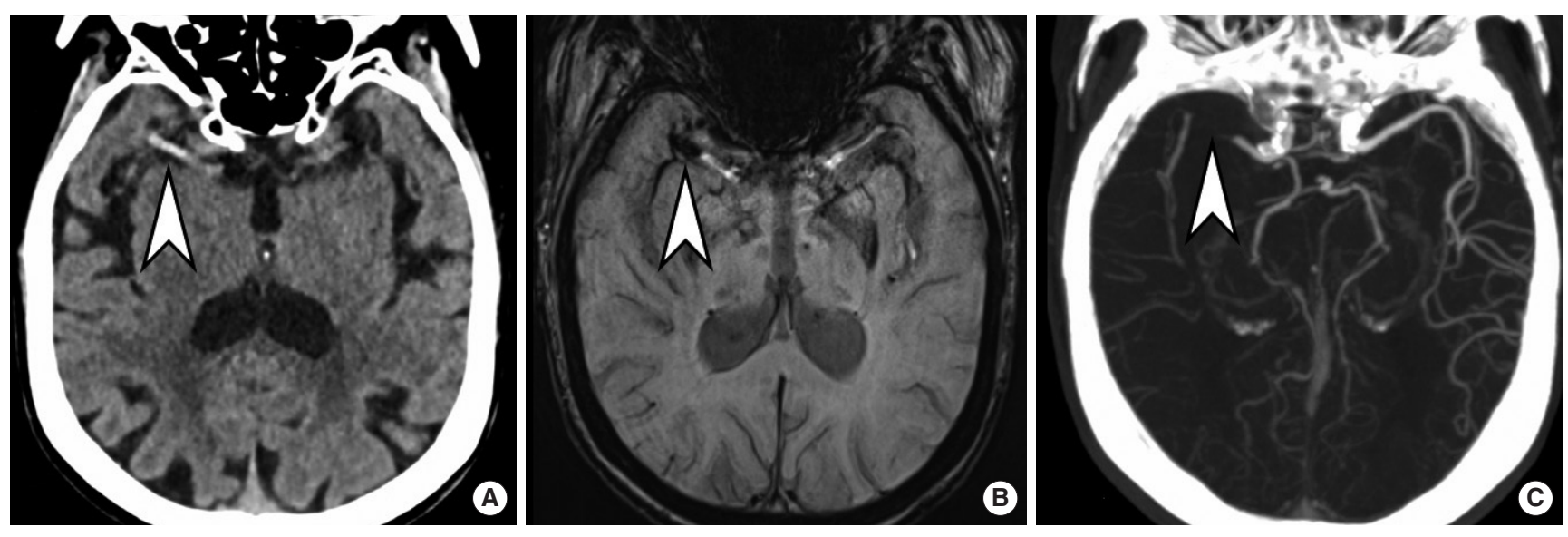

Supplementary Figure 1. Diagnosis of thrombus in imaging studies. (A) Hyperdense artery sign on CT scan (arrowhead), (B) Blooming artifact on the susceptibility-weighted image (arrowhead), and (C) Occlusion on CT angiography (arrowhead). CT-Computed Tomography. 
Supplementary Table 1. Thrombus histology according to the stroke subtypes

\begin{tabular}{|c|c|c|c|c|c|c|}
\hline Author, year & $\begin{array}{l}\text { Patient } \\
\text { No. }\end{array}$ & Device & Staining & Analysis & $\begin{array}{c}\text { RBC- } \\
\text { dominance }\end{array}$ & $\begin{array}{l}\text { Fibrin/fibrin-plate- } \\
\text { let-dominance }\end{array}$ \\
\hline Marder, 2006 ${ }^{1}$ & 25 & Merci & H\&E & Feature detection analysis & No difference & No difference \\
\hline Liebeskind, $2011^{2}$ & 50 & Merci & $\mathrm{HCtE}$ & $\begin{array}{l}\text { Semi-automated quantitation } \\
\text { using ImageJ }\end{array}$ & No difference & No difference \\
\hline Sato, $2012^{3}$ & 17 & Autopsy & Fibll, GPIlb/IIla, glycophorin A & $\begin{array}{l}\text { Semi-automated quantitation } \\
\text { using ImageJ }\end{array}$ & Cardiac & No difference \\
\hline Niesten, $2014^{4}$ & 22 & Merci, Trevo, Solitaire & $\begin{array}{l}\text { H\&E, Mallory's phosphotungstic } \\
\text { acid-hematoxylin, glycophorin } \\
\text { A, CD31 }\end{array}$ & Quantitation by consensus & Arterial & No differences \\
\hline Kim, $2015^{5}$ & 37 & Solitaire, Aspiration & platelet glycoprotein IIla, CD61 & $\begin{array}{l}\text { Semi-automated quantitation } \\
\text { using ImageJ }\end{array}$ & Cardiac & Arterial (fibrin) \\
\hline Ahn, $2016^{6}$ & 32 & Aspiration & HCtE, Martius scarlet blue, CD42b & Quantitation by software & Arterial & Cardiac (fibrin)* \\
\hline
\end{tabular}

$\mathrm{HEE}$, hematoxylin and eosin; RBC, Red blood cell.

\section{References}

1. Marder VJ, Chute DJ, Starkman S, Abolian AM, Kidwell C, Liebeskind $D$, et al. Analysis of thrombi retrieved from cerebral arteries of patients with acute ischemic stroke. Stroke 2006; 37:2086-2093.

2. Liebeskind DS, Sanossian N, Yong WH, Starkman S, Tsang MP, Moya $A L$, et al. CT and MRI early vessel signs reflect clot composition in acute stroke. Stroke 2011;42:1237-1243.

3. Sato $Y$, Ishibashi-Ueda $H$, Iwakiri T, Ikeda $Y$, Matsuyama $T$, Hatakeyama K, et al. Thrombus components in cardioembolic and atherothrombotic strokes. Thromb Res 2012;130:278-280.
4. Niesten JM, van der Schaaf IC, van Dam L, Vink A, Vos JA, Schonewille WJ, et al. Histopathologic composition of cerebral thrombi of acute stroke patients is correlated with stroke subtype and thrombus attenuation. PLoS One 2014;9:e88882.

5. Kim SK, Yoon W, Kim TS, Kim HS, Heo TW, Park MS. Histologic analysis of retrieved clots in acute ischemic stroke: correlation with stroke etiology and gradient-echo MRI. AJNR Am J Neuroradiol 2015;36:1756-1762.

6. Ahn SH, Hong R, Choo IS, Heo JH, Nam HS, Kang HG, et al. Histologic features of acute thrombi retrieved from stroke patients during mechanical reperfusion therapy. Int J Stroke 2016; $11: 1036-1044$. 